Macedonian Pharmaceutical Bulletin, 66 (Suppl 1) 109 - 110 (2020)

Online ISSN $1857-8969$

UDC: 616.5-056.3:665.585.5

DOI: 10.33320/maced.pharm.bull.2020.66.03.054

Short communication

\title{
Potential irritants and allergens in shampoos-type preparations
}

\author{
Isidora Milanovic ${ }^{1}$, Jasmina Bašić ${ }^{1}$, Danijela Pecarski ${ }^{1}$, \\ Dragana Dragaš Milovanović ${ }^{1}$
}

\author{
${ }^{I}$ Belgrade Academy of Professional Studies, Department Medical College of Professional Health \\ Studies, Cara Dušana 254, Zemun, Belgrade, Serbia
}

\section{Introduction}

The shampoos have the role to cleansing impurities from skin and hair surface at relatively low temperatures and for a short time. The shampoos need to have a beneficial effect on the scalp and hair, also prevent them from being damaged by external and internal factors. The shampoos use surface activea agents (SAAs) with an HLB value of 13-15 (according to Griffin scale), as a primary, which provide good washing, foaming, and removal of impurities with friction. They reduce the surface tension between impurities and water; peptize, emulsify or solubilize and remove them with the foam, rinsing with water. The secondary surfactants in shampoos are poorly foamed, wash well and have a lower irritant potential (Rulebook of cosmetic products, 2019).

The most commonly used as a primary surfactants are sodium lauryl sulfate (SLS) and sodium laurylethersulfate (SLES), which heavily degrease the skin and hair; and are combined with amphoteric surfactants betaine or sulfobetaine, as a secondary surfactants, which act as foam stabilizers, solubilizers and/or thickeners. Prolonged and repeated application of these agents changes the natural $\mathrm{pH}$ of the skin from slightly acidic $(\mathrm{pH}=4.5$ 6) to neutral and alkaline values, which corresponds to reproduction of the pathogenic microorganism.
Also, the corneal layer disrupts the ratio of proteins and structural lipids that provide a stable skin barrier function. The hydrolipidic film recovers very quickly, but long-term damage to the skin's barrier function occurs after repeated skin exposure to these SAAs and its cumulative. These disorders in the structure and function of the skin are manifested in the form of different skin conditions (dry skin, cumulative irritation, irritant and allergic dermatitis) (Pedersen et al., 2004).

\section{Materials and methods}

The declaration of composition of 10 types of foreign and 10 types of domestic production shampoos on the market of the Republic of Serbia was analyzed. The types and amounts of surfactants present in the basic role of shampoo were analyzed, with an emphasis on determining the presence of substances that have the potential to exhibit skin irritant or allergic reactions.

\section{Results and discussion}

SLS and SLES (about 30\%) are most often represented as primary surfactants in shampoos both, domestic and foreign in Serbia. These are preparations where, in addition to the content of SAAs (5-15\%), they are also indicated which are

\footnotetext{
*i.milanovic007@gmail.com
} 
SAAs used. The most common amphoteric SAA in shampoos is cocoamidopropylbetain (about 7\%), as a secondary surfactants as well as for reduction of the irritant effects of anionic SAAs.

In a large number of different studies, in addition to SLS and SLES, cocoamidopropylbetain, most frequently appears as a potential sensitizer or skin irritant (Goosens, 2005; Mangano et al., 2009). The effect of SLS on transepidermal water loss (TEWL) was also examined in relation to differences in age of subjects. A statistically significant increase in TEWL was measured in the younger group of subjects compared to the older group (Marrakchi \& Maibach, 2006).

Some of occupational disease guides, indicate the possibility of developing skin irritation or skin allergic reactions in professions such as hairdressers and beauticians, who come into contact with these two potential irritants daily (Bogadi et al., 2014). Cleaning the skin with alkaline soaps and bath preparations results in cumulative irritation. Usually irritant reactions are local, occur after 24 hours at the site of administration, and they are limited. The skin tests for the allergen identification are either negative or indicate irritating dermatitis (Goosens, 2005; Pederson et al., 2004).

The irritation potential of SLES or SLS derives from their ability to remove hydrolipid layer from surface excessively. The irritation potential of cocoamido propylbetain comes from the presence of impurities in the form of amines capable of producing nitrosamines in the skin (Jessop, 2015). Combination of two irritants, as confirmed by several studies, results in increased penetration and interreaction with structures in the skin, resulting in damage to the barrier function and it is possible to manifest irritating dermatitis (Pedersen et al., 2004).

A comprehensive analyzes of different type of SLS toxicity due to different routes of administration, give a positive judgment about safety of use of SLS, with precautions for persons prone to skin irritation or allergic reactions (Bondi et al., 2015).

\section{Conclusion}

The effects of combination of allergens and irritants, when compared to the response to the same substances alone, are very different. The effects of exposure to multiple allergens or irritants must be thoroughly investigated and documented.

The results of such studies would be of great importance for the safe application of shampoos. The declarations of these preparations should include information about possible effects of combination of irritants found in these preparations. It can be an important aspect in the prevention of contact and irritant dermatitis.

\section{References}

Bogadi, Š.A., Bubaš, M., Kerner, J., Macan, J., Pejnović, N., 2014. Pristup profesionalnim bolestima kože u medicine rada. Zagreb, 24.

Bondi, C.A.M., Marks, J.L., Wroblewski, L.B., Raatikainen, H.S., Lenox, S.H., Gebhardt, K.E., 2015. Human and Environmental Toxicity of Sodium Lauryl Sulfate (SLS): Evidence for safe use in household cleaning products. Environmental Health Insights, 9, 27-32.

Goossens, A., 2005. Contact allergy to hair care products, Book of Abstracts: 3rd Spring Symposium EADV, Sofia, 7.

Jessop, P.G., Ahmadpour, F., Buczynski, M.A., Burns, T.J., Green II, N.B., Korwin, R., Long, D., Massad, S.K., Manley, J.B., Omidbakhsh, N., Pearl, R., Pereira, S., Predale, R.A., Sliva, P.G., VanderBilt, H., Weller, S., Wolf, M.H., 2015. Opportunities for greener alternatives in chemical formulations. Green Chem. 17, 2664-2678.

Marrakchi, S., Maibach, H.I., 2006. SLS-induced irritation in the human face; regional and age-related differences. Skin Pharmacol Physiol. 19(3), 177-180.

Magnano, M., Silvani, S., Vincenzi, C., Nino, M., Tosti, A., 2009. Contact allergens and irritants in household washing and cleaning products. Contact Dermatitis 61, 33-341.

Pedersen, L.K., Johansen, J.D., Held, E., Agner, T., 2004. Augmentation of skin response by exposure to a combination of allergens and irritants - a review. Contact Dermatitis 50, 265-273.

Rulebook of cosmetic products. Official Gazette of RS, No.60/Aug,2019./. 